\title{
O impacto econômico e social da paralisação das obras públicas de infraestrutura
} The economic and social impact of the parallization of public infrastructure works El impacto económico y social de la paralisación de las obras públicas de infraestructura

\section{Pedro Emílio Amador Salomão}

ORCID: https://orcid.org/0000-0001-9451-3111 Universidade Federal dos Vales do Jequitinhonha e Mucuri, Brasil E-mail: pedroemilioamador@yahoo.com.br

Dayson Pereira Pêgo

ORCID: https://orcid.org/0000-0001-5564-7440 Universidade Presidente Antônio Carlos, Brasil E-mail: dpereirapego@gmail.com Arnon Roberto Rhis ORCID: https://orcid.org/0000-0002-4617-7333 Universidade Presidente Antônio Carlos, Brasil E-mail: profarnon@gmail.com Sandra Sofia Figueredo Coelho ORCID: https://orcid.org/0000-0002-7196-4945 Universidade Presidente Antônio Carlos, Brasil E-mail: sandrasofiaunipac@ hotmail.com

Recebido: 07/01/2019 | Revisado: 31/01/2019 | Aceito: 01/02/2019 | Publicado: 27/02/2019

\section{Resumo}

As obras públicas são essenciais para a prestação de bens e serviços à população, como também a ascensão do desenvolvimento econômico. Isso pode ser observado pelas obras de infraestrutura, que servem de suporte para toda a cadeia produtiva do país. O Brasil passa por um grande problema com relação ao número elevado de obras paradas que geram, assim, impactos negativos em diversos setores. Para tanto, é necessário que se revise a forma em que a administração pública conduz seus projetos, buscando melhorias, principalmente do no que diz respeito ao planejamento. Esse artigo apresenta o atual cenário das obras públicas paradas no Brasil, verificando suas causas, os setores mais afetados e os impactos provocados. Apresenta também, o posicionamento da administração pública para a retomada das obras e as possíveis medidas para que se evite a paralisação. Esse estudo se baseou em levantamento 
bibliográfico coletados de órgãos públicos oficiais, artigos científicos, cartilhas e livros. Visto esse cenário, este artigo verificou os valores médios das obras públicas que se encontram paradas, e quais são os valores necessários para que volte ao estado original. Com isso chegou-se a conclusão de a falta de planejamento em obrar públicas, que levam a sua paralização total, gera gastos exorbitantes aos cofres públicos.

Palavras-chave: Obras públicas; Paralisação; Planejamento; Impactos.

\begin{abstract}
Public works are essential for the provision of goods and services to the population, as well as the rise of economic development. This can be observed by the infrastructure works, which serve as support for the entire productive chain of the country. Brazil faces a major problem in relation to the large number of works that generate negative impacts in several sectors. To do so, it is necessary to review the way in which the public administration conducts its projects, seeking improvements, especially from the planning side. This article presents the current scenario of public works stopped in Brazil, verifying their causes, the sectors most affected and the impacts provoked. It also presents the positioning of the public administration for the resumption of works and possible measures to avoid paralysis. This study was based on a bibliographical survey collected from official public agencies, scientific articles, booklets and books. Given this scenario, this article verified the average values of the public works that are stopped, and what are the values necessary for it to return to the original state. With this came the conclusion of the lack of planning in public operations, which lead to their total paralysis, generates exorbitant expenses to the public coffers.
\end{abstract}

Keywords: Public works; Shutdown; Planning; Impacts.

\title{
Resumen
}

Las obras públicas son esenciales para la prestación de bienes y servicios a la población, así como el ascenso del desarrollo económico. Esto puede ser observado por las obras de infraestructura, que sirven de soporte para toda la cadena productiva del país. Brasil pasa por un gran problema con relación al número elevado de obras paradas que generan, así, impactos negativos en diversos sectores. Para ello, es necesario que se revise la forma en que la administración pública conduce sus proyectos, buscando mejoras, principalmente en lo que se refiere a la planificación. Este artículo presenta el actual escenario de las obras públicas paradas en Brasil, verificando sus causas, los sectores más afectados y los impactos provocados. Se presenta también, el posicionamiento de la administración pública para la 
reanudación de las obras y las posibles medidas para que se evite la paralización. Este estudio se basó en el levantamiento bibliográfico recogido de órganos públicos oficiales, artículos científicos, cartillas y libros. En este escenario, este artículo verificó los valores medios de las obras públicas que se encuentran paradas, y cuáles son los valores necesarios para que vuelva al estado original. Con ello se llegó a la conclusión de que la falta de planificación en obrar públicas, que llevan a su paralización total, genera gastos exorbitantes a las arcas públicas.

Palabras clave: Obras públicas; Paralización; Planificación; Impactos.

\section{INTRODUÇÃO}

O desenvolvimento do país está diretamente relacionado aos investimentos em obras públicas e a eficiente gestão de planejamento que antecedem esse empreendimento pela administração pública.

No Brasil o número de obras públicas paradas é muito elevado. De acordo com dados do MPDG - Ministério do Planejamento, Desenvolvimento e Gestão (2017), em levantamento feito pela CBIC - Confederação Brasileira da Indústria e Comércio (2018), existem cerca de 7.500 obras paralisadas ou em atraso, sendo em grande parte no campo de infraestrutura, que é responsável por significativa contribuição para a economia e qualidade de vida da população.

A crise financeira e política nos últimos anos contribui para esse quantitativo, entretanto, essa não é a única razão de números tão vultosos. Falhas no planejamento e execução pela administração pública também implicam efetivamente para esse problema, gerando aumento dos custos previstos e do tempo de execução do serviço.

Portanto, uma melhor logística na fase de planejamento poderia atenuar esses problemas, garantindo uma melhor efetividade na destinação dos recursos públicos e promovendo assim, a continuidade das obras dentro do orçamento e prazo previstos.

Assim, diante da situação do quantitativo de obras paradas se faz importante analisar a situação das obras públicas no Brasil, suas etapas de planejamento e execução, bem como os impactos sociais e econômicos acarretados por esse problema, sendo de suma importância a busca de alternativas para amenizar esses impactos. Desse mofo, o presente artigo tem por objetivo analisar a problemática de obras públicas paradas no Brasil e seus impactos. O presente trabalho tem como objetivo analisar a problemática de obras públicas paradas no Brasil, dando um foco na região do vale do Mucuri, Minas Gerais. 


\section{OBRAS PÚBLICAS DE INFRAESTRUTURA}

Segundo o Tribunal de Contas da União - TCU (2014), obra pública pode ser definida como toda construção, reforma, fabricação ou ampliação de qualquer bem público, executada de forma direta, quando a obra é feita pelo próprio órgão ou administração ou de forma indireta com a contratação de terceiros, realizada mediante licitação.

De acordo com a lei no 8.666/1993, licitação é a seleção da proposta mais vantajosa para a administração pública, sendo processada e julgada de maneira precisa em conformidade com os princípios básicos da legalidade, impessoalidade, moralidade, igualdade, publicidade, probidade administrativa.

O seguimento da legislação supracitada é de suma importância para a contratação e continuidade das obras públicas, não somente pela descrição dos aspectos técnicos e legais, mas por oferecer um amparo a administração pública na condução de seus projetos.

Segundo Vargas et al. (2009), projeto pode ser entendido como um planejamento com tempo finito em que o objetivo principal é criar um produto ou serviço específico. Enfatiza ainda que o projeto deve ser definido por uma sequência preestabelecida e lógica de eventos, com início e fim bem definidos.

É importante ressaltar, conforme Carvalho et al. (2017), que o objetivo básico de um projeto de construção é concluí-lo no prazo e dentro do orçamento, atendendo aos requisitos de qualidade estabelecidos e a outras especificações. Para conseguir atingir esse objetivo, os esforços devem ser contínuos, e isso não pode ser realizado sem um sistema de planejamento e controle eficientes.

Assim, o não cumprimento de procedimentos técnicos e legais, no que diz respeito a projeto, pode acarretar uma série de problemas como interrupções no andamento da obra, gerando dessa forma aumento nos custos previstos, atrasos e paralisações, bem como impactos diretos na qualidade de vida da população, visto que, a ideia principal de obras públicas é oferecer melhorias para a sociedade, concentrando-se principalmente em obras de infraestrutura.

Segundo o Gomide e Pereira (2018), o aumento de investimentos em infraestrutura é uma forma de se favorecer o crescimento econômico e o bem-estar social. Investimentos dessa natureza são geradores de ganhos e de produtividade e estão relacionados à demanda da sociedade por bens e serviços públicos de qualidade. 
A ampliação dos investimentos no país não se dará por mera vontade da administração pública, mas por severas mudanças nas políticas de governo e na melhoria da qualidade das instituições. Como é o caso da infraestrutura no país. Frischtak et al. (2016).

Um sistema infraestrutural pouco desenvolvido dificulta a expansão da economia, limita a operação de serviços essenciais para toda cadeia produtiva do pais, além do aumento em investimentos dessa natureza, é necessário a continuidade das obras já iniciadas que compõem todo o sistema.

\section{METODOLOGIA}

A fim de atingir os objetivos e, portanto, verificar as hipóteses, foi proposta uma metodologia para realização do pressente trabalho. Baseando-se em levantamento de informações, leitura, interpretação e escrita de acordo com as seguintes etapas:

$1^{\circ}$ ) Levantamento de informações através de dissertações de mestrado, teses de doutorado, artigos científicos, cartilhas e trabalhos técnicos na área de planejamento financeiro de obrar públicas;

$2^{\circ}$ ) Quantificação e qualificação de informações referente aos valores envolvidos em obrar públicas;

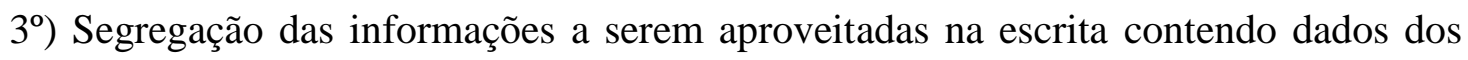
valores e quais as obras públicas que se encontram paralisadas;

$\left.4^{\circ}\right)$ Escrita do trabalho baseado nas informações levantadas.

\section{RESULTADOS E DISCUSSÃO}

De acordo com dados do Ministério do Planejamento, Desenvolvimento e Gestão (2017), existem cerca de 7.500 projetos inacabados no Brasil com recursos federais, entretanto, não é possível exemplificar com exatidão o número total de obras paradas, devido à escassez de dados que abranjam todo o universo de interesse.

Um levantamento de amostragem probabilística por conglomerado, foi realizado pela Confederação Nacional da Indústria - CNI (2017), com dados do MPDG (2017) que traz um quantitativo de obras paralisadas composto por 2.797 projetos que expõe a concepção de obras paradas, conforme o grau de execução no momento da paralisação. Para melhor 
descrição sobre obras paradas em determinado seguimento, a tabela 1 ilustra o quantitativo referente a obras de infraestrutura em atraso, além de obras de pequeno porte, que não são foco deste estudo.

Tabela 1 - Número de obras paralisadas, de acordo com o grau de execução.

\begin{tabular}{|c|c|c|c|c|c|}
\hline & $0 \%$ a $25 \%$ & $>25$ a $50 \%$ & $\begin{array}{c}>50 \% \text { a } \\
75 \%\end{array}$ & $\begin{array}{c}>75 \% \text { a } \\
100 \%\end{array}$ & Total \\
\hline Aeroportos & 5 & 2 & 6 & 3 & 16 \\
\hline Ferrovias & 1 & 2 & 1 & 1 & 5 \\
\hline Hidrovias & 1 & 3 & 1 & 0 & 5 \\
\hline Mobilidade Urbana & 6 & 1 & 0 & 1 & 8 \\
\hline Portos & 3 & 1 & 1 & 1 & 6 \\
\hline Rodovias & 8 & 6 & 11 & 5 & 30 \\
\hline Saneamento & 168 & 119 & 89 & 71 & 447 \\
\hline Total Infraestrutura & 192 & 134 & 109 & 82 & 517 \\
\hline Creches, pré-escolas & & & & & \\
\hline $\begin{array}{l}\text { e quadras esportivas } \\
\text { nas escolas }\end{array}$ & 330 & 366 & 453 & 213 & 1362 \\
\hline UBS's e UPA's & 23 & 39 & 35 & 59 & 156 \\
\hline Outros & 289 & 173 & 165 & 135 & 762 \\
\hline Total & 834 & 712 & 762 & 489 & 2797 \\
\hline
\end{tabular}

Fonte: (Ministério do Planejamento, Desenvolvimento e Gestão, 2017/CNI).

Observando a tabela 1, percebe-se a predominância de projetos paralisados que integram creches, pré-escolas e quadras nas escolas. Essas obras podem ser consideradas de pequeno porte, pois não apresentam aparentemente alta complexidade técnica ou custo 
financeiro elevado, fatores que podem ser determinantes para a não continuidade da maioria dos projetos. Essa realidade demonstra, assim, a dificuldade que a administração pública tem em dar prosseguimento aos projetos mesmo de pequeno porte.

Já as obras de infraestrutura (Aeroportos, Ferrovias, Hidrovias, Mobilidade urbana, Portos e Saneamento), totalizam um percentual menor de paralização. Entretanto, essas obras mesmo não sendo as líderes do ranking da paralisação, podem ser consideradas as de maior complexidade técnica e capital financeiro comprometido, fatores determinantes para a paralisação bem como a retomada das mesmas.

Ainda tendo como fonte de resultados do MPDG (2017), sob análise de um balanço composto por 922 obras retomadas em dezembro de 2017, constatou-se os principais motivos de paralisação. Os números mostram 362 projetos por abandono das empresas, 290 por problemas técnicos, 149 projetos por problemas financeiros, 35 projetos por questões ambientais, judiciais, desapropriação, órgãos de controle, além de 86 projetos paralização por outros motivos.

Essas causas evidenciam a necessidade de melhores projetos, de qualidade técnica mais aprimorada, principalmente na fase de planejamento. Com adoção dessas medidas poder-se-ia evitar em grande parte a paralisação de obras públicas no Brasil.

Como cita Amaral e Vieira (2018), sobre a importância do planejamento para execução de uma obra:

\begin{abstract}
'Sendo assim, é perceptível que uma obra sem planejamento está com poucas chances de êxito sem atrasos, imprevistos ou até acréscimo de custos. O planejamento deve ser feito analisando as condições atuais e também considerando o que virá depois, devem-se analisar as condições de início de uma obra e as condições que se terá no seu decorrer, de acordo com cada atividade, pois as condições tanto climáticas quanto econômicas mudam no decorrer da obra. (Amaral e Vieira, 2018, p. 20)'”.
\end{abstract}

É importante ressaltar que a crise político-econômica é um fator determinante para o não prosseguimento de algumas obras, pois a instabilidade financeira e a forma em que administração pública gere seus recursos causa impactos diretos no setor infraestrutural. 
A corrupção e o superfaturamento de obras públicas são também fatores importantes que devem ser analisados. Esses atos implicam em grande prejuízo à administração pública, como também paralisações por embargos judiciais e complicações fiscais.

Conforme Lima et al. (2015), aput Garcia et al. (2003), os principais atos de corrupção e fraudes em obras públicas são:

a) Venda de informações privilegiadas

b) Lobbying

c) Mudanças de regras

d) Facilitação de contratos

e) Fraudação de licitações públicas

f) Agilização de pagamentos

g) Alteração de qualidade e/ou especificações técnicas

h) Sobrepreço ou superfaturamento

Nesse sentindo, é importante retomar a lei $\mathrm{n}^{\circ}$ 8.666/93, que regulamenta as normas para licitação e contratos da administração pública, que valoriza a importância do seguimento da legislação aplicável e da efetiva fiscalização dos órgãos responsáveis para a minimização dos impactos provocados por atos que contrariam a lei mencionada.

De acordo com a CBIC (2017), estima-se que as obras públicas paradas no Brasil comprometam cerca de $\mathrm{R} \$ 76$ bilhões em recursos públicos. Entretanto, dimensionar toda a abrangência do problema é algo complexo. Torna-se necessário avaliar a importância dos bens e serviços comprometidos com a interrupção das obras, para que dessa forma, seja possível apresentar uma perspectiva dos impactos.

O mercado da construção, é um dos afetados, de acordo com a Fundação Getúlio Vargas (2017) e a ABRAMAT - Associação Brasileira da Indústria de Materiais de Construção (2017), toda cadeia produtiva da construção em 2016 movimentou R $\$ 460$ bilhões na economia, o que equivale a 7,3\% do PIB, conforme a Tabela 2.

Tabela 2 - PIB e Ocupação da Cadeia. 


\begin{tabular}{c|c|c|c|c}
\hline & \multicolumn{2}{c}{ PIB } & \multicolumn{2}{c}{ PESSOAL OCUPADO } \\
\hline & R\$ Milhão & $(\%)$ & Pessoas & \\
\hline Construção & 305.027 & $66,24 \%$ & 8.005 .663 & $69,06 \%$ \\
\hline Industria de Materiais & 54.334 & $11,80 \%$ & 663.997 & $5,73 \%$ \\
\hline Comércio de materiais & 39.432 & $8,56 \%$ & 992.741 & $8,56 \%$ \\
\hline Serviços & 23.306 & $5,06 \%$ & 553.085 & $4,77 \%$ \\
\hline Máquinas e equipamentos & 3.150 & $0,68 \%$ & 51.249 & $0,44 \%$ \\
\hline Outros fornecedores & 35.230 & $7,65 \%$ & 1.326 .208 & $11,44 \%$ \\
\hline Total da Cadeia & $\mathbf{4 6 0 . 4 7 8}$ & $\mathbf{1 0 0 , 0 0 \%}$ & $\mathbf{1 1 . 5 9 2 . 9 4 3}$ & $\mathbf{1 0 0 , 0 0 \%}$ \\
\hline
\end{tabular}

Fonte: FGV (2016).

Para Frischtak et al (2018), os conflitos da paralisação de obras ocorrem de maneira mais imediata sobre a demanda agregada, gerando um impacto direto aos trabalhadores em todas as etapas do projeto, como também em toda cadeia produtiva das empresas contratadas com seus subcontratados e fornecedores de bens e serviços, além da contribuição ao Estado através de tributos. E por suposto, tem um impacto indireto, na medida em que as rendas dessas empresas e pessoas se convertem em outros gastos, e assim sucessivamente. Neste sentido, menos obras em andamento impactam o produto e a renda do país em termos agregados, inclusive ao causar efeitos indiretos sobre todos os setores da economia.

Outro fator que deve ser analisado é a gama de impactos gerados pela paralisação de obras de infraestrutura na área de saneamento e o consequente impacto causado à população pela falta do serviço proposto.

O Brasil passa por grandes dificuldades para que o saneamento básico chegue a toda população. De acordo com estudo feito pelo Instituto Trata Brasil (2015), com dados Sistema Nacional de Informações Sobre Saneamento, 83,3 \% da população tem acesso a água tratada e apenas $51,92 \%$ tem acesso a coleta de esgoto, destes, somente $44,92 \%$ recebem tratamento. O instituto afirma ainda, com dados da Organização Mundial da Saúde, que cada R $\$ 1,00$ investido em saneamento gera economia de $\mathrm{R} \$ 4,00$ em saúde. 
Diante dessa realidade, pode-se sublinhar que o baixo investimento em saneamento no país, atrelado a um alto índice de paralisação das obras já iniciadas, tende a elevar o índice de doenças relacionadas a falta de saneamento, como o aumento de custas em internações.

Ao se analisar a retomada das obras públicas, primeiramente, é necessário que se examine a atual conjuntura da problemática no país, avaliando os setores mais afetados, para que dessa forma se delimite a melhor maneira para a retomada.

A criação do Programa Avançar em 2017 é atualmente a principal medida implementada pelo Governo Federal para catalogar e retomar as obras inacabadas. O programa conta com perspectiva de investimento de $\mathrm{R} \$ 130,97$ bilhões, originários do Orçamento Geral da União, Fundo de Garantia por Tempo de Serviço (FGTS) e de recursos de empresas estatais. A concretização desses investimentos proporcionaria significativa melhora no desenvolvimento econômico do país, confirmada pelo estudo realizado pela CBIC (2018), que demonstra um acréscimo de R 115 bilhões na economia caso todas as obras paradas abrangidas pelo programa fossem retomadas.

É importante ressaltar, que para a concretização da retomada dessas obras paradas e a continuidade sem novas interrupções. São necessárias correções nos principais motivadores das paralisações e, principalmente, na maneira em que o governo administra seus recursos financeiros e na forma que dá seguimento aos projetos de interesse público.

Nesse sentindo, de ação mais imediata, além das correções necessárias nos demais motivadores é imprescindível o reestabelecimento da economia. Em razão do elevado número de obras paradas existentes no país e do alto valor agregado na retomada.

De acordo com a CBIC (2017), estima-se que as obras públicas paradas no Brasil comprometem cerca de $\mathrm{R} \$ 76$ bilhões em recursos públicos. Além dos recursos comprometidos com a paralização de uma obra, é importante ressaltar o aumento dos recursos empenhados na retomada, devido a deterioração da estrutura inacabada e aumento do valor contratual no momento da licitação para quando a obra for reinicializada.

Para MARTINS (2018), as paralisações podem ser ainda mais prejudiciais à economia brasileira, já que muitas delas perdem o sentindo econômico e social, não justificando sua conclusão.

Nesse sentido, é possível notar a complexidade da retomada de uma obra, atentando para o desperdício de recursos públicos envolvidos com a paralisação. Dessa forma, é importante uma análise de toda estratégia usada na retomada. 


\section{CONSIDERAÇÕES FINAIS}

Através do estudo realizado, foi possível verificar o quantitativo de obras públicas paradas no Brasil e suas causas, analisando como essas interrupções comprometem o desenvolvimento econômico e social do país. Atentando para a importância da continuidade do sistema infraestrutural como forma de expansão da economia e favorecimento de serviços essenciais para a população.

O elevado número de obras públicas paradas tem causado diversos impactos negativos, seja economicamente através do desperdício de dinheiro público, geração de empregos e venda de insumos para a construção, bem como na ausência do serviço proposto a população devido as paralisações.

Sendo assim, são necessárias contínuas melhorias na forma em que a administração pública executa seus projetos, buscando alternativas para diminuição do número futuro de paralisações através de melhores projetos, com qualidade técnica aprimorada e planejamento prévio em todas as etapas do empreendimento. É necessário também, maior observância da lei $\mathrm{n}^{\circ} 8.666 / 1993$ que regulamenta a contratação de obras públicas pela administração pública, objetivando-se a diminuição de fatores determinantes de paralisações.

Para tanto, entende-se que é imprescindível a reestruturação da economia como uma das estratégias para a retomada das obras paradas no Brasil, tendo em vista que o direcionamento financeiro a essas obras devem ser aplicados, levando em consideração os objetivos da efetivação das mesmas. Em contrapartida, se não houver um alinhamento desde o início da obra até a conclusão desta, acarretará vários prejuízos à população.

\section{REFERÊNCIAS}

Amaral, g. H. S. N., \& vieira, p. H. S. (2018). Atraso em obras públicas-um levantamento na prefeitura de anápolis.

Brasil. (1993). Lei $n^{\circ}$ 8.666, de 21 de junho de 1993. Regulamenta o art. 37, inciso XXI, da Constituição Federal, institui normas para licitações e contratos da Administração Pública e dá outras providências. Diário Oficial da União. 
Carvalho, M. T. M., de Paula, J. M. P., \& Gonçalves, P. H. (2017). Gerenciamento de obras públicas (No. 2284). Texto para Discussão.

CBIC (Câmara Brasileira da Industria da Construção); Pereira, L. C. B. (1998). A reforma do Estado dos anos 90: lógica e mecanismos de controle. Lua Nova, 45, 49-citation_lastpage.

CNI (Confederação Nacional da Indústria) - Alcantara, L. F. B. (2016). Atrasos de obras: uma correlação com problemas no gerenciamento (Bachelor's thesis, Universidade Tecnológica Federal do Paraná).

da União, T. D. C. (2014). Obras Públicas. Recomendações Básicas para a Contratação e Fiscalização de Obras de Edificações Públicas. $4^{a}$ edição Brasília.

Gomide, A. D. Á., \& Pereira, A. K. E. (2018). Governança da política de infraestrutura: condicionantes institucionais ao investimento.

Frischtak, C. R., Davies, K., \& Noronha, J. (2016). O financiamento do investimento em infraestrutura no Brasil: uma agenda para sua expansão sustentada. Revista Econômica, 17(2).

Fundação Getúlio Vargas, FGV; Associação Brasileira da Indústria de Materiais de Construção, ABRAMAT. Castro, B. H. R. D., Barros, D. C., \& Veiga, S. G. D. (2013). Panorama da indústria de bens de capital para a construção civil.

Neri, M. C. (2007). Trata Brasil: saneamento e saúde. Rio de Janeiro: FGV, IBRE, CPS.

Lima, V. G. D. M. Sobrepreço e superfaturamento de obras públicas e indicadores educacionais: Uma Análise De Suas Relações Nos Estados Brasileiros.

Cavalcante, P. (2017). Gestão Pública Contemporânea: do movimento gerencialista ao pósNPM (No. 2319). Texto para Discussão.

MPDG (Ministério do Planejamento Desenvolvimento e Gestão). Retomada de Obras Paradas. Brasília - DF. 2017.

VARGAS, Ricardo Viana. Gerenciamento de Projetos, Estabelecendo Diferenciais Competitivos. Rio de Janeiro - RJ, 2009.7 $7^{\mathrm{a}}$ ed. 
Res., Soc. Dev. 2019; 8(5):e1085915

ISSN 2525-3409 | DOI: http://dx.doi.org/10.33448/rsd-v8i5.915

Porcentagem de contribuição de cada autor no manuscrito

Pedro Emílio Amador Salomão - 40\%

Dayson Pereira Pêgo - 20\%

Arnon Roberto Rhis - 20\%

Sandra Sofia Figueredo Coelho - 20\% 